\title{
EL COMENTARIO DE TEXTO EN LA DIDACTICA DE LA HISTORIA ANTIGUA
}

\author{
MANUEL ABILIO RABANAL ALONSO \\ Universidad de Alicante
}

\begin{abstract}
Es necesario para los estudiosos de la Historia entrar en contacto directo con las fuentes escritas. De ahí la importancia del conocimiento de la metodología y aplicación práctica del comentario de textos como elemento fundamental en la didáctica de la Historia, en el caso presente de la Historia Antigua.
\end{abstract}

For scholars of History, it is necessary to be familiarized with the written sources. This justifies the importance of the methodology of text commentary and its actual application, as a basic question in the didactics of History, and in this case of Ancient History.

\section{OBJETIVOS DEL COMENTARIO DE TEXTOS}

La clasificación o taxonomía de los objetivos tiene unos planteamientos rigurosos, para alcanzar progresivamente cotas cada vez más elevadas, hasta llegar a adquirir una capacidad auténtica de juicios y valoración con respecto a cualquier texto.

La programación tiene varios objetivos, según Ronald G. Cave (1), cuyo progreso se desarrolla en orden ascendente y que es aplicable al Comentarios de Textos:

1. Adquisición de conocimientos a través de los textos.

2. Comprensión de contenidos.

3. Aplicación general de los conocimientos comprendidos.

4. Análisis de los conocimientos comprendidos y aplicados. zados.

5. Evaluación o valoración de los conocimientos comprendidos, aplicados y anali-

Para todo ello existe un método con el fin de ordenar los objetivos señalados.

En el punto uno, referido a los conocimientos, el profesor tiene como misión fundamental: marcar y señalar cuál debe ser el proceso de aprendizaje, para llegar a adquirir el nivel de contenidos de información que parezcan convenientes, según el nivel de enseñanza. Además la clase de conocimientos puede a su vez implicar otros procesos más complejos como el de relacionar conocimientos o incluso juzgarlos.

En lo que respecta a la Comprensión, que constituye el punto dos, es necesario fijar la atención en el significado y contenido del texto. Para ello el primer paso que debemos dar, al enfrentarnos con textos de Historia Antigua, es el de la traducción del texto, interpretando la forma, aclarando alusiones, con el fin de llegar al fondo del contenido del texto, matizando o explicando, si es necesario, el sentido de algunos términos empleados en el original.

(1) Introducción a la programación educativa, p. 92 ss. Ed. Anaya 1979 (Edición inglesa, 1971). 
En tercer lugar entramos en el punto de la Aplicación, en el que lo más importante es el uso de la generalización y el encuadre histórico, e incluso podríamos hacer referencias comparativas a otras circunstancias o momentos históricos similares; todo ello sin perder de vista el contenido real del texto, sin hacer digresiones que seguramente no encajarían en nuestro planteamiento.

El apartado de Análisis se refiere a una jerarquización de las ideas del texto y sus posibles interrelaciones, fijándose explícitamente en los contenidos desde la perspectiva dẹl momento histórico, desde la importancia del testimonio que se ofrece y desde la línea de pensamiento del autor. Por lo tanto se debe aclarar todo lo que en principio nos acerque a una mejor comprensión. Aquí podemos incluir la aplicación de nombres, términos, instituciones, etc., con el fin de conseguir una auténtica objetividad crítico-histórica del comentario.

La Síntesis consiste en unir los distintos elementos y partes del texto, para formar una unidad, un todo cuantificable históricamente. En este sentido entramos en el campo de la creación, componiendo un esquema definitorio de las ideas fundamentales, para fijarnos en la estructuración y vinculaciones de tales ideas.

El último paso en el Comentario es la Evaluación, que supone la combinación final de todas las anteriores categorías de objetivos. Básicamente evaluar es corroborar contenidos, criticar y valorar el texto. La crítica abarca dos campos, que deben ser sometidos a la consideración del comentarista: la interpretación de lo que se dice en el texto, y la exactitud de las afirmaciones hechas. Convendría además añadir la validez de las circunstancias de la época.

Según todas las categorías de objetivos podemos llegar a establecer un auténtico esquema de Comentario de texto:

\section{DESARROLLO DEL ESQUEMA DE COMENTARIO}

\section{FASE I: INFORMACION}

\section{a) Naturaleza del texto:}

- Texto Documento.

- Texto de autor fuente.

- Texto lectura.

- Texto narrativo.

-Texto jurídico.

- Texto estadístico.

- Texto de economía.

- Textos de Hemeroteca.

- Textos varios.

\section{b) Enmarque histórico-geográfico:}

- Historia interna o externa de un país.

-Aspectos internacionales.

-Aspectos regionales, provinciales, locales.

-Biografías, autobiografías, relatos familiares.

- Ambientación del texto en el momento histórico.

-Dónde se escribió el texto:

- lugar geográfico

- ubicación social 
- lugar político

- lugar administrativo

- lugar religioso

- Contexto económico.

c) Filiación del texto y su importancia:

\section{Autor:}

- Que el texto tenga autor.

- Que el texto no tenga autor: problemas de paternidad. Texto con pseudónimo.

- Texto anónimo: remite al contexto histórico-geográfico.

d) Cronología:

- Textos fechados.

- Textos sin fecha: Se fecha desde la crítica misma del texto.

- Modo de fechar textos sin fecha:

- Por términos.

- Por instituciones.

- Por nombres propios o comunes.

- Acontecimientos.

\section{FASE II: INTERPRETACION}

a) Aspectos externos:

- Texto y expresión.

- Texto y testimonio.

- Fuentes y ciencias auxiliares utilizadas.

- Tipo de historia utilizado:

- Metodología del texto:

- Enfoques:

- Narrativo.

- Pragmático.

- Genético.

- Ideológico.

- Materialista.

- Diacrónico.

- Sincrónico.

- Etnográfico.

- Retrospectivo.

- Cíclico.

- Progresista.

- Genético.

- Erudito.

- Analítico.

- Estadístico.

- Como historia total. 


\section{b) Aspectos internos:}

1. En orden a la valoración real del texto:

- Captación de las ideas básicas del texto.

- Aclaración de pasajes o alusiones.

- Area de problemas tratados.

- Vigencia cronológica y espacial.

- Hipótesis y tesis.

2. En orden a la crítica:

- Crítica de exactitud.

- Validez de las circunstancias del autor.

- Crítica de interpretación.

- Validez de las circunstancias de la época.

\section{FASE III: CONCLUSION}

a) Síntesis del fragmento.

b) Encuadre histórico.

c) Errores, lagurnas, deficiencias.

d) Autoridad del autor o fuente.

e) Sentido general del texto.

f) Alcance e interés último del texto.

g) Valoración personal.

h) Proyección histórica del contenido del texto.(2)

Conviene no olvidar, como planteamiento didáctico general, qué es lo que se debe y se quiere enseñar y cuál es el nivel de conocimientos que debe alcanzar el alumno.

A la hora de seleccionar unos textos, para comentarlos en la clase, el profesor tiene que plantearse unas metas, contando con el interés y el grado de disposición favorable de los alumnos.

El texto debe servir para crear situaciones de interés, de amenización y de agrado en el alumno, al ofrecer un material histórico desde una perspectiva de análisis directo.

Cada profesor puede tener muy claro cuáles son las lecciones que va a impartir, pero con frecuencia deja de lado un planteamiento de objetivos y de forma de conseguir esos objetivos. Falta en muchos casos una verdadera filosofía del curso. Y lo que quizá sea aún más lamentable, algunos profesores no se preocupan de que unos resultados positivos o negativos de un curso pueden y deben servir de pauta para cambios futuros, si no sustanciales en lo que respecta a los contenidos, sí necesarios para una forma más adecuada de aproximación al interés del alumno.

Quien deliberadamente olvida que hay que contar con dicho interés del alumno, que cualquier forma de impartir las clases es susceptible de mejora, está negando su propia condición de docente. Y quien prescinde del comentario de textos como herramienta docente, junto con el comentario de mapas, diapositivas, o distintos objetos arqueológicos, está olvidando las formas de hacer y de enseñar la Historia.

El cambio didáctico, según dice Escolano (3), podría ayudar a solucionar muchos problemas derivados de la masificación y requiere unas condiciones nuevas en materia

(2) La explicación de los distintos apartados puede encontrarse en el libro Comentario de textos históricos. Método, selección y ejemplos prácticos, de LARA PEINADO, F. y RABANAL ALONSO, M. A. Lérida, 1981 ( $3 .^{a}$ edición).

(3) ESCOLANO, A., 1978, «La innovación didáctica en la Universidad: problemas y posibilidades», p. 19; Patio de Escuelas, I, Enero-Junio, Universidad de Salamanca (I. C. E.). 
de organización, personal, medios y actitudes. Debemos innovar, pero sin utopías, contando con que la realidad universitaria no ofrece facilidades para innovaciones profundas. «Pero también es cierto, y existe evidencia experimental sobre ello, que los ensayos de innovación pedagógica pueden activar los cambios de orden estructural o, al menos, promover la conciencia de su necesidad». (4)

\section{EJEMPLOS PRACTICOS}

\section{TEXTO PARA COMENTAR (traducción)}

«Fue entonces cuando Tiberio Sempronio Graco, ciudadano noble, animado por una gran ambición, singularmente dotado del don de la expresión oral y gozando de la mayor popularidad en sus diferentes aspectos, pronunció, al llegar al tribunal, un discurso de extrema gravedad para los pueblos de Italia; habló de ellos como pueblos particularmente aptos para la guerra y vecinos de los romanos por la sangre, pero en vías de deslizarse poco a poco hacia la miseria y la despoblación, sin ninguna esperanza de resurgimiento. Con respecto a los esclavos, los consideraba de malos propósitos y malos soldados, dispuestos a traicionar a sus amos; añadió una alusión a las recientes pruebas que en Sicilia los amos habían aguantado por parte de sus esclavos, quienes, como anteriormente, habían crecido en número por exigencia de los trabajos del campo... Después de pronunciar este discurso, puso en vigor la ley que prohibía la posesión de más de quinientas medidas de tierra. Los hijos de los propietarios eran objeto de un añadido en la ley anterior que les otorgaba la mitad de este valor. Para el resto que sobraba, tres ciudadanos elegidos se sucederían anualmente con la finalidad de repartirlo entre los necesitados».

Apiano, «Cinerras Civiles», I, 9, 35-36.

\section{FASE I. INFORMACION}

a) Naturaleza del texto. Este punto puede prestarse a confusión ya que existen dudas sobre su clasificación como texto-documento o texto de autor fuente.

Nosotros nos inclinamos más por la segunda posibilidad, ya que el autor tiene una clara entidad histórica. No obstante el texto abunda en connotaciones narrativas.

b) Extracción del texto. Al tratarse de un texto que relata el contenido de un discurso político, no cabe duda que éste ha de proceder de un personaje conocido en las esferas políticas; tal es el caso de Tiberio Sempronio Graco, Tribuno de la Plebe en el año 133 a. C.

c) Extensión y contorno históricos. Con respecto a la extensión del texto diremos que se ocupa de un problema tan importante en el contexto italiano del último siglo de la República, como es el de la reforma agraria.

Como consecuencia de las conquistas que la República realizó a lo largo del siglo II a. C. se había aumentado el «ager publicus». Pero el reparto de estas tierras, como ocurría en tiempos anteriores no fue efectuado entre los más pobres para que se dedicaran a su explotación en propiedad. La aristocracia monopolizó esta propiedad. A pesar de la expresa prohibición, algunos senadores se apoderaban de las tierras emprendiendo una explotación agrícola de tipo «capitalista».

Si a esto se une que para la explotación y gracias a las conquistas había aumentado el número de esclavos, se comprende que el pequeño propietario quedara a expensas del gran terrateniente «capitalista».

(4) La misma cita de la nota (2). 
En este contexto histórico aparece la figura de Tiberio Sempronio Graco que se encargará de promover una reforma agraria, que más tarde intentará ser continuada por su hermano Cayo.

d) Autor. Se trata de Apiano, historiador griego nacido en Alejandría sobre el año 95 de J. C. Ejerció cargos administrativos, y siendo ciudadano romano, pasó a Roma. En tiempo de Antonino Pío compuso una historia analítica de las conquistas romanas («Romaiká»), en 24 libros, la mayor parte de los cuales se han perdido.

Su historia es de una gran objetividad y contiene gran cantidad de datos sobre los pueblos vencidos por Roma y sobre las guerras civiles.

e) Cronología. El texto, a pesar de no presentar fecha alguna, se escribe dos siglos y medio después de sucedidos los hechos narrados.

La fecha de nacimiento de Apiano y su vinculación cultural con el reinado de Antonino Pío, nos hace suponer que el texto debió ser escrito hacia mediados del siglo II de nuestra era.

f) Lugar de redacción. No sabemos a ciencia cierta dónde se escribió el texto, pero el que Apiano ejerciera algún cargo administrativo induce a pensar que fuera escrito en Roma o en alguna otra ciudad importante.

\section{FASE II. INTERPRETACION}

En esta fase no seguiremos el esquema rígidamente observado en la primera y daremos una mayor importancia a los aspectos internos del texto que son, en definitiva, los que nos harán llegar a una valoración más justa del texto en cuestión. Ello no quiere decir que los aspectos externos carezcan de importancia; quedan relegados a un segundo plano ante el papel de primer orden que ocupan los aspectos internos.

a) Aspectos externos del texto. El original es un texto en lengua griega; presenta un estilo puramente narrativo y se limita a contar lo que sucedió en un momento determinado, no siendo el autor testigo directo de los hechos, buscando un encadenamiento lógico para llegar al fondo de las causas y consecuencias que se descubren de.un modo retrospectivo y con un enfoque eminentemente analítico.

\section{b) Aspectos internos del texto}

1. Valoración real del texto. El tribuno de la plebe, Tiberio Sempronio Graco, en el culmen de su popularidad pronuncia un discurso que contiene graves términos en los que se refiere a los pueblos de Italia, a la situación de los esclavos, etc. Tras el discurso proclama una ley de reforma agraria, que va a traer violentas consecuencias.

Tiberio S. Graco accede al Tribunado de la Plebe «gozando de la mayor popularidad en sus diferentes aspectos». Pero no queda demasiado claro en qué aspectos de esa popularidad destaca Tiberio: Interviene en la III Guerra Púnica junto a Escipión Emiliano lo que sin duda le granjea gran popularidad debido a su éxito. A pesar de ser de procedencia noble, lo que para la plebe supone una cierta tendencia hacia la enemistad, se inclina a favor de los más menesterosos, postura que le resulta positiva. Además goza de las simpatías de los círculos helenizantes de Roma, y también entre los intelectuales.

Aclarado este aspecto, nos disponemos a tratar los problemas incluidos en el texto.

Hemos considerado necesario la división del texto en tres partes bien diferenciadas: el origen y filiación de Tiberio Graco, el discurso de éste, y la ley de reforma agraria.

Respecto al origen de Tiberio Graco hay que decir que era hijo del primer Tiberio Sempronio Graco (cónsul en el 177 y 163, y censor en el año 169 a. C.) y de Cornelia II, hija ésta de Publio Cornelio Escipión, el Africano, gran vencedor de Aníbal. Tiberio Graco tuvo un hermano, el no menos famoso Cayo Graco, y una hermana, Sempronia, que se casaría con el destructor de Cartago, Escipión Emiliano.

Tal cercanía al círculo de los Escipiones (de entre los que lucharon en la III Guerra Púnica destacaban Cayo Lelio y Polibio) influyó sobre manera en la formación de opi- 
niones políticas de Tiberio, y es posible que de aquí pueda salir uno de los embriones de la idea de reforma agraria.

Algún motivo ha de haber para que Tiberio se presente a las elecciones a Tribuno de la Plebe en el verano del 134 a. C. Veleyo Patérculo nos menciona la «locura revolucionaria» que rodeaba a los Gracos. Según su hermano Cayo, Plutarco nos cuenta cómo Tiberio Graco, atravesando la Etruria «vio desierta una hermosa región que no tenía más que extranjeros y bárbaros como agricultores y pastores». Otro motivo más para intentar una reforma.

Influido por ideas filantrópicas e incluso igualitarias provenientes de algunos pensadores helenísticos, Tiberio intenta la candidatura y consigue ser Tribuno de la Plebe para el año 133.

Es ahora cuando llega el discurso de Tiberio con el que pretende convencer a los senadores y a la Asamblea de la necesidad de una ley que reforme la distribución del «ager publicus».

El discurso, en su contenido general, tiene una finalidad política, aunque está cargado de diferentes connotaciones, ya sea de tipo social, económico, demográfico o incluso bélico.

En el aspecto social, vemos cómo Tiberio esboza de pasada un punto que luego, con Cayo Graco, será caballo de batalla. Nos referimos a la concesión de ciudadanía a los pueblos de Italia, que aparece cuando habla de pueblos «vecinos de los romanos por la sangre». Esto era de suma importancia, ya que únicamente la categoría de ciudadano daba derecho a la posesión de tierras.

También desde el punto de vista de lo social, pero con una notable influencia de lo moral, nos encontramos en el texto con los esclavos, a los cuales Tiberio considera de «malos propósitos». ¿De dónde vienen estos malos propósitos? ¿Qué van a originar?

El hombre, por naturaleza libre, no puede tolerar la esclavitud; de ahí sus intentos por permanecer en esa condición de libre. Esto conlleva acciones rebeldes; pero, ¿Hacia dónde van enfocadas estas acciones rebeldes? Para los esclavistas, estas acciones suponen un atentado contra la propiedad (los esclavos, simples objetos). Para los esclavos es un intento de volver al estado natural, libre, lo cual no es malo.

Por otra parte, a pesar de que la condición de esclavo es una realidad social, Tiberio Sempronio Graco ve la necesidad de un planteamiento distinto respecto a los esclavos, para que no se vuelvan a repetir las rebeliones (Sicilia), que no hacen más que generar malestar social.

Pero no sólo era la rebelión de los esclavos lo que impulsaba a Tiberio a plantear el proyecto de renovación en el campesinado. El darse cuenta del peligro que representaba la concentración de gentes sin derechos fue el principal motivo que lo lanzó a perfilar definitivamente su proyecto de ley agraria. La reforma trataría de detener el desarrollo de la esclavitud y de hacer renacer el antiguo grupo de los campesinos, base principal en la que se asentaba el poderío militar de Roma.

Entrando en el apartado económico, no podemos dejar de observar que Tiberio Graco anuncia que, de no llevarse a cabo la reforma, grandes extensiones de tierra quedarían reducidas a la miseria y su recuperación sería imposible. A su vez, se hace necesaria la sustitución de la mano de obra esclava por la del pequeño propietario, que al trabajar sus tierras vería aliviada su ya asfixiada economía.

Este problema de la mano de obra ha de ser matizado. Al ser empleados los esclavos en los latifundios, la productividad de éstos es enormemente superior a la de la pequeña extensión. Además la venta de la producción es casi un monopolio de los terratenientes capitalistas, y los trabajadores con pequeñas parcelas apenas pueden vender lo necesario para subsistir, y en ocasiones ni siquiera eso (si de los doce hijos que tuvo Cornelia. madre de los Gracos, a pesar de las buenas condiciones en que se desenvolvía, só- 
lo sobrevivieron tres, ¿qué resultaría de una familia menesterosa?). Es por esto por lo que Tiberio Graco considera vital, valga la redundancia, revitalizar el trabajo del pequeño agricultor para que la miseria no asole los campos de Italia.

En el aspecto demográfico, cabe destacar dos hechos que se interrelacionan: el aumento del número de esclavos y la despoblación de las tierras.

Ya hemos insistido en las consecuencias que la proliferación de esclavos traía para el pequeño propietario. La imposibilidad de competir supone el abandono de los campos para establecerse en lugares más apropiados. Ello repercute en el aumento de población, sobre todo en las ciudades, y la despoblación de la tierra. Estamos ante un éxodo rural que puede traer ruinosas consecuencias.

Finalmente, en lo que al discurso respecta, hay que hacer resaltar un contenido bélico que puede venir como consecuencia de lo anteriormente expuesto: estos pueblos, de clara tendencia a la guerra, pueden clamar por sus derechos y originar unas luchas crueles. Tiberio no quería el desorden en esos pueblos, y por ello mismo su objetivo - dice Apiano- «no era tanto proporcionar la felicidad a los pobres (cosa evidentemente importante), como el de obtener de ellos fuerza bélica eficiente para el Estado».

Se califica también a los esclavos como «malos soldados». Pero estos esclavos no podían formar parte de un ejército organizado sino que se limitarían a tener que defender a su señor. De ahí que muchas veces, animados por «malos propósitos», estuvieran «dispuestos a traicionar a sus amos».

Pronunciado el discurso, llegamos a la ley en la que también debemos distinguir varios apartados, de repercusiones en la economía, sociedad y política.

Al parecer, esta ley tiene unos antecedentes; probablemente existió al menos alguna ley anterior, que bien podría ser la de Cayo Licinio y Lucio Sextio del 376 a. C., pero ésta jamás se aplicó. Dicha ley, como las anteriores, se basaba en el principio jurídico por el que quedaba para el Estado la propiedad de todo el «ager publicus» que no se había enajenado según formas regulares: así, podía recuperar las tierras ocupadas o alquiladas y disponer de ellas a su gusto.

Económicamente, la ley supone una restricción de las grandes propiedades en favor de las pequeñas, lo que va a suponer el detrimento de los intereses aristocráticos y de gran cantidad de senadores que habían acaparado esas tierras. ¿Iban a dejarse despojar de manera impune de sus propiedades, algunas de ellas bien cultivadas y reformadas con fuertes inversiones económicas? Está claro que no.

Todo ello va a suscitar rencillas y oposiciones que, en última instancia, costarán la vida a Tiberio y, más tarde, a su hermano Cayo Sempronio Graco.

De todos son conocidas las medidas que dicha ley contenía: limitación de la propiedad a 500 yugadas $(4$ yugadas $=1 \mathrm{Ha}$.) por ciudadano, más la mitad por cada hijo. El resto se repartiría en parcelas de 30 yugadas para la explotación, previo pago de un simbólico tributo.

Socialmente, lo que Tiberio pretendía era el beneficio de los más necesitados y para ello no reparaba en el daño que pudieran sufrir los antiguos propietarios, que lógicamente se oponían al proyecto.

Vencidas las dificultades, la ley sale con fuerza aunque la muerte de Tiberio hace que ésta no cuaje.

Políticamente hemos de destacar un hecho: la creación de una comisión de tres ciudadanos para supervisar los trabajos de reparto.

En un principio, estos triunviros serán el propio Tiberio, su suegro, Apio Claudio, y su hermano Cayo Graco, con ilimitados poderes para confiscar los terrenos sobrantes y repartirlos, tras su parcelación entre los ciudadanos pobres.

Llegamos al final de nuestro análisis viendo las consecuencias de la ley. Debido a la oposición de los senadores, Tiberio intenta vencerla dentro de la legalidad, sin conse- 
guirlo. La cabeza, más bien el principal instrumento de la oposición, era el Tribuno Octavio; Tiberio Graco y sus demás colegas se ponen de acuerdo para destituirlo «por mayoría de votos», aduciendo que actúa contra los intereses del pueblo. Esto va a indignar al Senado.

Aprobada la ley y creada la comisión - con los problemas que trajo-, llega el escándalo del testamento del rey Atalo II de Pérgamo, que Tiberio quiere emplearlo a favor de la reforma. Si a lo mencionado se le une que, ilegalmente, Tiberio busca su reelección para continuar su obra, no cabe otra medida para la oposición que la de dar muerte a Tiberio Graco y a sus partidarios.

Diez años después, su hermano puso de nuevo en marcha la reforma con leyes como la «Primera Ley de Cayo Graco», la «Lex Sempronia de Provincia Asia», «Lex frumentaria», o la que daba lugar al establecimiento de colonias. La muerte de Cayo Graco supuso el final de la reforma.

Haciendo un breve balance de ésta, podemos decir que al final triunfó totalmente la propiedad privada. No obstante, en algunas zonas, la pequeña y mediana propiedad fueron restauradas. La comisión de triunviros fue disuelta y se decretó que las tierras estatales no podían ser divididas de nuevo. Y aunque la reacción fue fuerte en un primer momento, no se logró destruir totalmente la obra de los Graco.

Si bien la situación de los campesinos mejoró durante cierto tiempo, el nacimiento de la pequeña propiedad no era posible dentro de una sociedad de base esclavista; así la cuestión agraria no pudo ser resuelta. La reforma no se transformó en revolución al no abarcar al esclavo, y también por sus profundas contradicciones internas. En palabras de Salustio, Roma dará una imagen atormentada después de la revolución de los Graco.

\section{En orden a la Crítica}

En este aspecto hemos de ser breves y nos limitaremos a decir que no cabe extrapolación aventurada alguna, pues a nuestro entender el autor, Apiano, no ha dicho más que lo que quería decir.

Respecto a la exactitud del texto creemos que se ajusta a la realidad, aunque quizás haya que hacer alguna matización: Tiberio Graco no puso, por sí mismo, en vigor ninguna ley. Con ello queremos decir que sólo una persona instituida como poder absoluto puede poner en vigor una ley sin consultarla a nadie. Lo que sí hizo Tiberio fue luchar por la implantación de dicha ley, lucha en la que se le consideró como deseoso del poder, y que le costaría la vida. Creemos que esta apreciación es importante.

En cuanto a las circunstancias de la época y que concurren en el autor, opinamos que Apiano no debió verse influido por nada; sólo su voluntad de escribir Historia le llevó a relatarnos este pasaje.

\section{FASE III. CONCLUSION}

El texto propuesto trata de la «rogatio» que Tiberio Sempronio Graco, Tribuno de la Plebe en el $133 \mathrm{a}$. de C., hace ante el tribunal tras pronunciar un discurso en el que pone de manifiesto la necesidad de una reforma agraria.

En todo el texto cabe destacar la existencia de una laguna importante: el aspecto religioso no se menciona en ningún momento. No sabemos por qué, pero nada nos hace pensar que se haya omitido voluntariamente.

Salvando las distancias con otros autores, Apiano es un autor menor, lo que no implica que su estudio no sea recomendable y su veracidad haya de ponerse en duda.

Positivamente el texto significa el intento de solución de un problema que asola la Italia del siglo II a. de C.: el problema agrario. En el aspecto negativo debemos decir que la reforma llegó tarde, cuando la gran propiedad ya está arraigada. 
Personalmente opinamos que tras los intentos de reforma de los hermanos Graco, se produjo una serie de hechos de vital importancia: siguió un siglo de luchas que no lograron reformar la República, sino hacerla desaparecer. Ni las buenas intenciones de los Graco, ni la dictadura de Sila, ni los intentos de restauración senatorial de Pompeyo, ni el intento de «monarquía cesarista» pudieron evitar el advenimiento del Imperio.

\section{BIBLIOGRAFIA}

ANDRE, J. M. y HUS, A. 1975: La Historia en Roma. Buenos Aires.

AYMARD, A. y AUBOYER, J. 1960: Roma y su Imperio (Historia general de las civilizaciones, Tomo II). Barcelona.

BICKERMANN, E. 1970: "The Gracchi and the Italian Slavery», Comm. au Ve, Congrès Int. d'Hist. Ec. Leningrado.

BLOCH, L. 1965: Luchas sociales en la antigua Roma. Buenos Aires.

BRUNT, P. A. 1973: Conflictos sociales en la República romana, EUDE, Buenos Aires.

ELLUL, J. 1970: Historia de las Instituciones de la Antigüedad. Madrid.

GAGE, J. 1976: Le chute des Tarquins et les débuts de la République romaine. París.

GUARINO, G. A. 1975: La rivoluzione della plebe. Nápoles.

KOVALIOV, S. I. 1973: Historia de Roma, Madrid.

LARA PEINADO, F. y RABANAL ALONSO, M. A. 1981: Comentario de textos históricos. Método, selección y ejemplos prácticos. Lérida ( $3 .^{\mathrm{a}}$ edición).

MARIN CORREA, M. y otros, 1970: Los Graco, Barcelona. (Nueva Historia Universal, Tomo I, «Los tiempos antiguos»).

NICOLET, C. 1977: Rome et la conquête du monde méditerranéen-1-Les structures de l'Italie primitive. París.

PARETI, L. y otros, 1978: El Mundo Antiguo, Barcelona. (Historia de la Humanidad, Tommo II).

UTCHENKO, S. L. 1978: Cicerón y su tiempo, Barcelona.

VERNET GINES, J. 1971: Las reformas de los Gracos, Barcelona. (Historia del Mundo, Tomo III).

Conocido el esquema general del comentario de texto, se puede fácilmente llegar a la simplificación de dicho esquema. De cada profesor dependen, una vez conocida y puesta en práctica la mecánica del comentario, estimular el trabajo de comprensión del alumno, pudiendo en todo momento reconducir los planteamientos previos a la lectura y posterior comentario de cualquier texto. De esta forma el docente participa activamente, eliminando prejuicios de enfoque y visión de una época o acontecimiento determinados.

Como se verá en este segundo comentario, se prescinde de parte del articulado en las Fases de Interpretación y Conclusión, sin restar rigor a la captación y asimiliación de los contenidos. Se demuestra así que el comentario de textos históricos exige un método y su aplicación práctica, pero sin duda ninguna podrán utilizarse directrices distintas, aunque similares en lo esencial.

Con todo ello alcanzaremos una valoración más adecuada del paso del hombre y comprenderemos de un modo directo y vivo la Historia. 


\section{TEXTO PARA COMENTAR (TRADUCCION)}

Después de la conquista de Anzio, Tito Emilio y Quinto Fabio llegan a ser cónsules... Ya en su primer consulado Emilio había propuesto entregar tierras a la plebe; y así su segundo consulado había despertado entre las poblaciones rurales la esperanza de obtener su ley; por su parte, los tribunos toman de nuevo el proyecto, ya que se habían tropezado a menudo con la oposición de los cónsules, pensando que podían obtener el apoyo del cónsul. Los poseedores de la tierra, y la mayoría de los senadores lo eran, deplorando que uno de los jefes del Estado tomara como trampolín una política tribunicia y se hiciera popular distribuyendo las tierras de otros, habían traspasado todo su descontento de los tribunos al cónsul. Un terrible conflicto habría estallado si Fabio no hubiese encontrado una solución que no perjudicaba a ningún partido: «La guerra mantenida el año anterior bajo la dirección y auspicios de T. Quinctio dejaba una buena cantidad de tierra arrebatada a los Volscos; Anzio, por su proximidad y posición ventajosa de ciudad marítima, se aprestaba a recibir una colonia: así, sin suscitar quejas de los actuales propietarios, se haría accesible la tierra a la plebe y el Estado encontraría la calma de nuevo.

Tito Livio, III, 1, 1-6

\section{COMENTARIO}

\section{FASE I. INFORMACION}

\section{a) Naturaleza de texto}

Bajo el aspecto de la naturaleza del texto, éste se puede identificar como un escrito del tipo «autor-fuente»; la redacción corresponde a uno de los grandes historiadores romanos de la antigüedad, Tito Livio, quien, bajo un lenguaje prosaico, nos muestra un aspecto problemático de la época republicana: la lucha entre patricios y plebeyos y el intento de conseguir derechos y privilegios por parte de estos últimos.

El escrito también se puede enclavar en el grupo de textos jurídicos, pues recoge la llegada al puesto de cónsules, que con su actitud política defienden derechos de la plebe, reflejando después la problemática y el descontento de las «clases» propietarias y de los senadores, entablándose una especie de lucha de «clases» entre los estamentos privilegiados y la plebe, llegando a los posteriores acuerdos y pactos tras lo cual se procede al reparto de los territorios entre la gente de la plebe, territorios conseguidos tras la guerra con los Volscos en la región de Anzio.

\section{b) Extracción del texto}

El origen del texto de Tito Livio se enmarca en un problema claramente político. La lucha entre los patricios y los plebeyos y la llegada al cargo de cónsules de los primeros representantes de la plebe supone un período de inestabilidad política. Nos muestra aspectos de política interior como son los problemas por los cuales atravesaba la República, como la lucha entre patricios y plebeyos y aspectos de política exterior como la guerra con los Volscos y la apropiación del territorio de Anzio, en la época de comienzo de la expansión y de la ofensiva romana en la Italia Central.

\section{c) Extensión y contorno histórico}

El texto lo encuadramos en la historia de la república romana, en los comienzos de la época expansiva en la Italia Central. 
Los problemas de las luchas entre patricios y plebeyos son una constante en la historia de la república romana, que se prolongaron más de dos siglos y que surgieron ante la perspectiva de la plebe romana de conseguir una igualdad de derechos políticos, una legislación sobre los derechos, evitando las causas en muchos casos de esclavitud, y el derecho de acceso al «ager» público.

El descontento de la plebe por su falta de derechos origina una lucha que transcurre en beneficio de la plebe, con diversos períodos positivos y negativos; creación de asambleas tribales, elección de tribunos de la plebe, codificación de leyes en las XII tablas, admisión para cargos civiles y religiosos, problemas en la agricultura, admisión de matrimonios mixtos, etc.

La tensión y las luchas entre pueblos bárbaros, galos, samnitas, luchas con Pirro, etcétera, hacen que la mayoría del ejército esté formado por gente de la plebe (más numerosos), las conquistas y la expropiación por Roma de territorios hacen más fácil la solución del problema a favor de los plebeyos, las cuales, muestran una habilidad grande al elegir sus representantes. Estas, entre otras, son causas del posterior triunfo de la plebe en el conflicto.

El origen de la problemática territorial que refleja el texto hay que buscarlo en época monárquica; entre las concesiones de privilegio que los monarcas hacen a diversas familias, que posteriormente ocuparían rango y posiciones de privilegio en la sociedad romana.

En resumen la extensión abarca la Roma repúblicana en su expansión territorial por la Italia Central y así se citan las campañas contra los Volscos que dan a entender un comienzo de las pretensiones expansivas.

El contorno histórico es el de un momento de crisis en una sociedad envuelta en las luchas entre patricios y plebeyos, época de altibajos, de inestabilidad social, y de pretensiones sociales por parte de la plebe.

\section{d) Cronología}

La fecha que se puede atribuir al texto es aproximadamente el 494 o $493 \mathrm{a}$. de C., fase inicial de la República Romana.

Período caracterizado por las tensiones entre patricios y plebeyos (según el relato tradicional, las luchas comenzaron en estas fechas). Se señala en el texto analizado que ocurrió un año después de las hostilidades con los pueblos Volscos, datación relativa que más refrenda la fecha aproximada, dada para el documento. Encuadramos en definitiva el escrito en la época inicial de la República en Roma.

\section{e) Lugar de Redacción}

Es de suponer que el lugar de redacción del texto fue territorio de Roma o incluso la misma ciudad, ya que hace referencia a hechos que sólo podían ocurrir en la ciudad de Roma como son el hecho de proponer leyes y ser rechazadas o no por el Senado.

Se citan de pasada otros lugares que fueron provincias y ciudades de Roma como Anzio pero que no tienen nada que ver con el lugar de redacción del texto.

$\mathrm{Al}$ no ser un desconocido oficial, sino el relato de un historiador, la situación geográfica del lugar de redacción es más difícil, pues no se da a conocer, aunque por el carácter oficialista y político que refleja el relato se supone que fue la propia ciudad de Roma el lugar de redacción del presente escrito histórico pero no sabemos si fue su lugar real de ejecución.

Las condiciones para la ejecución de la obra como necesidad de bibliotecas, relatos de la época o textos históricos anteriores, nos remiten también a Roma. 


\section{FASE II: INTERPRETACION}

\section{a) Aspectos Externos}

El texto en su forma está escrito en un lenguaje claro y plenamente históriconarrativo. El autor refleja, como si estuviera narrando o haciendo crónica (aunque en momentos pueda dar opiniones personales), un hecho ocurrido en un período determinado de la historia de Roma.

El autor del escrito pertenece al siglo I a. C., por lo tanto no pudo ser contemporáneo de los hechos que narra lo que podría ser un inconveniente en cuanto a la veracidad del escrito. Refleja éste una realidad de lucha entre patricios y plebeyos (en los comienzos de la República) con el intento de estos últimos por conseguir una serie de derechos, realidades favorables y situaciones positivas, aunque siempre se ha alabado más la obra histórica de Tito Livio, por su estilo que por su veracidad; pienso que el autor como historiador debe reflejar una realidad pura y clara sin divagar ni tomar partido por una $u$ otra tendencia (en el caso de este escrito) pues si no lo hiciera así no estaría haciendo historia real.

En la época Imperial Tito Livio continúa siendo republicano. Sintiendo por Roma un fervor religioso, Livio admite sólo como director de la Historia al pueblo romano, destinado por los dioses al dominio del mundo, por su fuerte y sobria virtud, por su espíritu de concordia y por su religiosidad.

Livio no considera la historia con espíritu filosófico o político, sino con ánimo épico, patriótico y religioso. Su pasión le hace aceptar todas las leyendas. Pone en boca de sus personajes bellísimos discursos, que sirven para dar variedad y gravedad a la narración. Esta es suelta, ordenada y sobria, armoniosa y llena de poesía lo que hace de Livio (a pesar de haberle reprochado algún censor de «provincialismo paduano»), un apasionado cantor de Roma así como un gran prosista.

En este caso Tito Livio no toma partido, ni deforma la narración pues sólo refleja una situación, narrando hechos y opiniones sobre un problema de dos tendencias opuestas. Métodos auxiliares utilizados por el autor para elaborar el texto, son muy difíciles de enumerar. Es evidente que, como historiador, el estudio de documentos y fuentes pertenecientes a esa época serían la ayuda necesaria para elaborar el escrito, pues Tito Livio no fue contemporáneo de los hechos.

La historia política y económica de esa época es, a mi entender, la que dio al autor la mayoría de datos para este escrito, incluso el derecho y la geográfia política en lo que se refiere a campañas militares y extensión geográfica del territorio romano.

El autor en el texto sólo quiere hacer referencia a una situación de conflictos entre dos «clases», patricios y plebeyos, reflejando una época de inestabilidad política y de expansión, al señalar la conquista de nuevos territorios, expansión que confirmará el poder de Roma en la Italia Central.

Pienso que la intencionalidad del escritor es firmemente narrativa, al mostrarnos un hecho, que sirve de testimonio para un momento concreto de la historia de Roma, sin intentar tomar partido.

En cuanto a la metodología el autor refleja una concepción de la historia como una sucesión de hechos, como un proceso evolutivo con respecto a las conclusiones de los plebeyos frente a los patricios, aunque tome datos de hechos ocurridos en época anterior al escrito referidos a la guerra con los Volscos como solución del problema.

Las causas y las razones de los acontecimientos son tratados un poco de pasada haciéndo más hincapié en el hecho concreto de la proposición de la ley, pasando por las protestas del Senado, hasta la solución final.

La metodología es mixta o no definible. El autor da un enfoque analítico de los he- 
chos y de sus posibles consecuencias apoyado en el enfrentamiento entre las dos tendencias, aunque realmente lo que trata de hacer Livio es historia.

\section{b) Aspectos Internos}

El texto refleja la problemática entre patricios y plebeyos, la crítica de los propietarios y de los recaudadores en la persona del cónsul (magistratura típicamente patricia), al intentar, mediante una política de favor, ganar el aprecio del pueblo, afrontar el problema del reparto de tierras, favoreciendo a los estamentos menos privilegiados, apoyando la política expansionista de Roma en la Italia Central y la solución al problema mediante el reparto de territorios conquistados a los Volscos.

El área de los problemas tratados en el texto queda definido por el Estado. Problema de lucha de «clases» entre patricios y plebeyos aunque en este escrito aparezca como presunto «defensor» de los problemas de la plebe las personas de los cónsules.

La especulación sobre los terrenos dedicados al cultivo era prácticamente un derecho de las clases patricias, aunque ahora con el comienzo de las luchas sociales se procura repartir terrenos entre los estamentos plebeyos, causa por la cual el Senado y los propietarios veían en estas tierras un modo de presión y enriquecimiento y por ello estaban en desacuerdo con las leyes propuestas por el cónsul Emilio.

Los tribunos de la plebe, que aparecieron a raíz del empeoramiento de la situación de la plebe hacia el 494 AC, chocaban con la oposición del Senado, de los cónsules y de los patricios en conjunto y vieron en la postura de Emilio un modo de favorecer el proyecto de reparto de tierras que casi siempre era abortado por los patricios.

En cuanto a la recogida de hechos bélicos se hace referencia a la guerra mantenida con los Volscos, primeras campañas realizadas para el afianzamiento de Roma en la zona Central de Italia.

Los problemas de las luchas entre patricios y plebeyos surgen por la situación de estos últimos en la sociedad romana, pues llegaban en ocasiones a caer en esclavitud por problemas de deudas (causa de la aparición de los primeros tribunos de la plebe, elección basada en las asambleas de la plebe por tribus a partir del 471 a. C. con las leyes del tribuno de la plebe Publio Valerio), además de la carencia de derechos políticos, de cargos, etc.

Hay que señalar en el texto el aspecto referido a una actitud en desacuerdo con la situación real que achacan al cónsul Emilio sus compañeros de cargo, los senadores y los grandes propietarios, con el consiguiente olvido de que el problema estaba en los tribunos de la plebe y no en el cónsul, pues son estos tribunos quienes se aprovechan de la situación para intentar lograr sus viejas pretensiones.

La solución viene reflejada en el hecho de que Fabio se encuentra con unos territorios conquistados a los Volscos aptos para ser colonizados, cultivados y explotados comercialmente; el reparto de éstos proporciona la solución adecuada sin deterioro de los intereses de los senadores y grandes propietarios.

Es interesante destacar que consideran al cónsul como una persona nunca coincidente con las pretensiones tribunicias, denominando los territorios para repartir entre los plebeyos como propios de la clase senatorial y de los terratenientes, afirmando el elitismo de la política del Senado para con los terratenientes en perjuicio del pequeño propietario y de las personas necesitadas de tierras de cultivo o de posibilidades de explotación en otras áreas económicas como el comercio.

En cuanto a la crítica del documento, diremos que no podemos dudar a primera vista de la veracidad del escrito de Tito Livio, pues las referencias que hace de las luchas son comprobables por la situación histórica del momento referido por el texto. 
Se adelanta a los hechos en el momento que «opina» que la solución de Fabio resultó el punto fundamental para evitar un conflicto, pero pienso que esta opinión es aceptable históricamente.

El lenguaje utilizado, al menos en la traducción, es claro y no ofrece lagunas que pudieran ser importantes o incorrecciones léxicas o de sentido. Su estilo es claro, característica típica de Tito Livio.

Las notaciones sobre hechos concretos como la batalla con los Volscos o la subida al poder consular de los personajes citados así como las características políticas y económicas de la región de Anzio, son reflejadas con absoluta corrección histórica; como se dijo antes, Tito Livio, piensa hacer historia. La veracidad y rigor estilístico del autor son aceptables por el prestigio como historiador de Tito Livio; además la lectura del texto no refleja partidismo, aunque se puede acercar, al menos tímidamente, a las posturas democráticas de los tribunos de la plebe, quizá por la propia postura política, por el léxico o por la importancia de la estructura del texto, la manera de colocar las frases referentes a los tribunos o cónsules defensores de la plebe, en una situación más relevante en el texto, como si lo referente a los senadores o propietarios terratenientes perteneciese a un segundo plano.

Creo que Tito Livio no intenta agradar a una determinada clase ni atraerse al público con este escrito; sólo, como he repetido varias veces, intenta hacer historia.

Ante la postura de los cónsules, cabe pensar que esa actitud de reparto de tierras para cultivo entre la gente de la plebe, tiene más de astucia política para conseguir confianza que de generosidad social; realmente esta actitud es característica de épocas de conflictos entre patricios y plebeyos, situación similar a la que tuvo lugar en Grecia al introducir entre la gente baja del «demos» personajes procedentes de la aristocracia «disfrazados» para lograr sus pretensiones reales.

La actitud de Emilio no ofrece dudas, pues lo que dice y lo que hace lo enfrentan con la clase elevada de los patricios, aunque realmente, la importancia, al menos en número, de los plebeyos es evidente y con el paso del tiempo su importancia política y social crecerá y no podemos negar rotundamente que Emilio intentara conseguir algo más que una igualdad social ante el Senado.

\section{FASE III: CONCLUSION}

Tras la batalla de Anzio, Tito Emilio y Quinto Fabio llegan a ser cónsules. Emilio en su primer consulado intenta repartir tierras a la plebe; los tribunos esperan de él una política similar. Las clases altas repudian la intención de Emilio, tratándole de oportunista. Esto está a punto de acabar en conflicto a no ser por la solución de Fabio, que propone distribuir entre la plebe tierras conquistadas el año anterior a los Volscos, y esta solución evita el conflicto, puesto que no perjudica a nadie y da paso a una época de tranquilidad.

El texto nos lleva a la época inicial de la República romana caracterizada por las luchas entre patricios y plebeyos y caracterizado, también, por el afianzamiento de la posición romana en la Italia Central.

Refleja el texto cómo poco a poco la plebe alcanza apoyo (no siempre desinteresado) de grupos sociales antes identificados con los patricios, Senado y grandes propietarios. La plebe pronto alcanzará cotas importantes de relativa igualdad en derechos políticos, económicos y sociales.

En el texto no se aprecian errores importantes. La lectura del texto refleja una situación real y verificable históricamente; la validez de los hechos narrados en el escrito son corroborados por la personalidad del escritor y por la historia de la República romana. 
Las características de los hechos reflejados parecen coincidir con la estructura de un comunicado político y social de una época y hemos de pensar que el autor, al no ser contemporáneo de los hechos, para la elaboración del texto, debía basarse en el estudio de otros textos más antiguos.

Cabe anotar que Tito Livio debió aclarar el significado de la «ayuda» que el cónsul presta, con la ley, a los tribunos de la plebe. Las circunstancias políticas en la Roma republicana podrían hacer que un cónsul, que teóricamente debería estar de parte de las «clases» patricias, apoyara, por intereses personales, a los tribunos de la plebe. La realidad es que los cambios en esta época se sucedieron rápidamente y de igual manera aparecían leyes de apoyo a la plebe como se dictaban otras contrarias a sus intereses. Con el tiempo son los plebeyos los que consiguen una mayoría de derechos, y solucionan sus problemas más acuciantes, como el acceso a las tierras del «ager» público o la solución al problema de las deudas.

La autoridad de Tito Livio está, creemos, plenamente verificada al ser uno de los fundamentales historiadores de la Edad Antigua. Sus obras han sido más consideradas por su estilo que por su contenido, pero pensamos que en este caso el reflejo de la situación y del conflicto están conseguidos y con seguridad muy acertadamente.

La aportación del texto de Tito Livio nos permite identificar la época y el problema nos introduce en el estudio de la problemática de la lucha de «clases» de la época; el texto es válido para hacer comprender la evolución de la política de clases en la Roma republicana.

El sentido general del texto hace referencia a una época de tensiones entre patricios y plebeyos, una época en la que la plebe comienza a tomar conciencia de su poderío, más potencial que real, en política o en el ámbito social, entre las pretensiones de las clases patricias de dominio territorial y político. La inteligencia política de los cónsules como Emilio se pone de manifiesto al elaborar una ley que pone a las clases inferiores de la plebe en un puesto de relativo privilegio y de auge social y político y que coloca al Senado y a las clases terratenientes en contra de una política que consideraban opuesta a la norma tradicional a caballo entre la actitud consular y la sociedad terrateniente y senatorial romana.

Destaca la actitud de los senadores y terratenientes, al considerar a los territorios del Estado («ager» público) como pertenecientes de pleno derecho a su clase y nunca atribuibles a la plebe.

La matización que realiza Tito Livio, al anotar que la solución de Fabio de distribuir los territorios conquistados a los Volscos el año anterior entre la plebe fue la solución al problema y evitó una fuerte lucha social, es acertada, pues la tensión de la sociedad en aquella época hacía estallar la chispa que promovía disturbios sociales de difíciles consecuencias.

Es positivo el hacernos ver la situación de discriminación de las clases más bajas frente al poderío político y económico de los patricios.

Las pretensiones de las «gentes» o poblaciones rurales eran necesarias para una estabilidad económica y política que afectara a toda la sociedad y no sólo a una clase privilegiada.

La oposición que tenían por parte de los cónsules era normal pues defendían los intereses de una «clases» privilegiada desde la época momárquica y los privilegios económicos de esta clase eran difíciles de eliminar de un solo golpe.

La solución que se da al problema territorial que refleja el texto evitaría un problema que podía haber acabado en guerra civil o en disturbios graves.

La problemática social que se refleja en el texto tuvo que ocurrir debido a la situación ante todo social y económica de la plebe, los impuestos que acababan en casos en esclavitud o la imposición de normas altamente negativas para las pretensiones de la ple- 
be de conseguir terrenos del «ager» público; con ello toman conciencia quienes se veían superiores en número pero inferiores en derechos.

El alcance último del texto nos hace introducirnos en las consecuencias a las que la lucha entre patricios y plebeyos lleva a la sociedad romana de la República.

El reflejo de una sociedad en crisis basada en los privilegios, controlada por patricios y el intento por parte de la clase plebeya que con toda razón intentan conseguir derechos que merecen, por ser la clase mayoritaria de Roma como fuerza social quedan claramente expresados.

El texto es un reflejo positivo que muestra una sociedad que intenta cambiar; el autor, Tito Livio, intenta narrarnos con precisión histórica una situación conflictiva que acabará con una solución provisional al problema socio-político, pero no acabará con las pretensiones de la plebe que no ha hecho más que iniciar el camino de la reivindicación.

\section{BIBLIOGRAFIA}

BICKERMANN, E. 1970: "The Gracchi and the Italian Slavery», Comm. au Ve, Congrès Int. d'Hist. Ec. Leningrado.

BLOCH, L. 1965: Luchas sociales en la antigua Roma. Buenos Aires.

BRUNT, P. A. 1973: Conflictos sociales en la República romana, EUDE, Buenos Aires.

ELLUL, J. 1970: Historia de las Instituciones de la Antigüedad. Madrid.

GAGE, J. 1976: Le chute des Tarquins et les débuts de la République romaine. París.

GUARINO, G. A. 1975: La rivoluzione della plebe. Nápoles.

NICOLET, C. 1977: Rome et la conquête du monde méditerranéen - 1-Les structures de l'Italie primitive. Paris.

LARA PEINADO, F. y RABANAL ALONSO, M. A. 1981: Comentario de textos históricos. Método, selección y ejemplos prácticos. Lérida ( $3 .^{\mathrm{a}}$ edición). 